\title{
Magnitude and Factors Associated with Self-Medication Practices among University Students: The Case of Arsi University, College of Health Science, Asella, Ethiopia: Cross-Sectional Survey Based Study
}

\author{
Shimelis Adugna Bekele', Mesele Damte Argaw ${ }^{2 *}$, Alemayehu Worku Yalew ${ }^{3}$ \\ ${ }^{1}$ Zaf Pharmaceuticals PLC, Addis Ababa, Ethiopia \\ ${ }^{2}$ Private Health Sector Project, Addis Ababa, Ethiopia \\ ${ }^{3}$ Addis Continental Institute of Public Health, Addis Ababa, Ethiopia \\ Email: adugna27@gmail.com, "mdamte5@gmail.com, alemayehuwy@yahoo.com
}

Received 14 May 2016; accepted 24 June 2016; published 27 June 2016

Copyright (C) 2016 by authors and OALib.

This work is licensed under the Creative Commons Attribution International License (CC BY). http://creativecommons.org/licenses/by/4.0/

(c) $\underset{\mathrm{EY}}{\mathrm{B}}$ Open Access

\section{Abstract}

Background: Self-medication is the selection and use of medicines by individuals to treat selfrecognized illnesses or symptoms without any medical supervision. It resulted in wastage of resources, increases in resistance of pathogens, and causes health hazards such as adverse drug reactions, prolonged suffering and drug dependence. Despite this fact, studies on the subject matter indicated that health science students continued to practice $\&$ recommend self-medication to society. Accordingly, the purpose of this study was to estimate the prevalence of self-medication among students of Arsi University College of Health Science and investigate factors associated with it. Methods: A cross-sectional quantitative study with three months illness recall was conducted in Arsi University College of Health Science students from January to February 2015. Data were collected randomly from each department using self-administered questionnaires. Data entry was made using Epi-Info version 3.5.2 and analysis was done using SPSS IBM version 20. Results: From a total of 575 questionnaires distributed, 548 questionnaires with a response rate of $95.30 \%$ were collected back assessed as complete, $70.8 \%(388 / 575)$ reported at least one episode of an illness during three months prior to the day of the questionnaire, and $77.10 \%(299 / 388)$ of them accessed to and practiced self-medication during the study period. Students reported for the study period commonly perceived illnesses such as headache $169(46.50 \%)$, gastrointestinal disease $102(34.10 \%)$ and respiratory tract infection $95(31.80 \%)$ accessed mainly antibiotics 179 (59.90\%) and analgesics $143(47.80 \%)$ mostly from drug retail outlets $184(61.50 \%)$. The odds of

\footnotetext{
${ }^{*}$ Corresponding author.
}

How to cite this paper: Bekele, S.A., Argaw, M.D. and Yalew, A.W. (2016) Magnitude and Factors Associated with Self-Medication Practices among University Students: The Case of Arsi University, College of Health Science, Asella, Ethiopia: Cross-Sectional Survey Based Study. Open Access Library Journal, 3: e2738. http://dx.doi.org/10.4236/oalib.1102738 
being female university student was 2 fold accessed self-medication than their counter part males with Adjusted Odds Ratio (AOR) 1.84 with 95\% Confidence Interval (CI): $1.01-3.34, p=0.046$. With regards to field of studies, students of midwifery were 3 folds accessed self-medication than their counter part students of medicine (AOR 2.78; $95 \% \mathrm{CI}=1.03,7.39, p=0.043$ ). Those students who accepted self-medication for low income segment of the population 2 folds accessed selfmedication than their counter part who disagree (AOR 1.76; 95\%CI $=1.02,3.06, p=0.04)$. The major reasons indicated for self-medication by respondents were perceived mildness of their illness $132(44.1 \%)$, poor quality of routine health care services $81(27.1 \%)$ and it saves their time $60(20.3 \%)$. Most respondents had a positive attitude towards practicing self-medication as especially, they believed a prospective health professionals \& low income segments of the populations have a right to practice self-medication $(p<0.05)$. Conclusions: Significant numbers of students were self-medicated in this study with antibiotics as major accessed drugs. Being female was significantly associated with self-medication. Conducting tailored behavioral change communication by the health authorities, universities and other stakeholders is recommended.

\section{Keywords}

Ethiopia, Health Science, Practice, Prevalence, Self-Medication, Students

Subject Areas: Epidemiology, Public Health

\section{Introduction}

The World Self-medication Industry defines self-medication as the treatment of common health problems with medicines especially designed, labeled and approved for use without medical supervision [1]. Self-medication can also be defined as the use of drugs to treat self-diagnosed disorders or symptoms, or the intermittent or continued use of a prescribed drug for chronic or recurrent disease or symptoms. It may include the use of herbs, the retention and re use of prescription drugs or the direct purchase of prescription-only drugs without medical input [2].

Several studies revealed that inappropriate self-medication results in wastage of resources, increases resistance of pathogens and generally entails serious health hazards such as adverse drug reactions, prolonged suffering and drug dependence. It also cause incorrect manner of administration, incorrect choice of therapy \& masking of severe disease [3].

A study conducted in Jimma University showed that $45.9 \%$ of the students with perceived illnesses practiced self-medication [4]. The incidence of self-medication within university students in other similar studies was found to be 76\% in Karachi, 54\% in Turkey, 88\% in Croatia and 94\% in Hong Kong [5]. In another study conducted in Addis Ababa and central Ethiopia, the magnitude of self-medication was as high as $50 \%$ [6]. The study carried out in North West Ethiopia showed 27.2\% self-medication prevalence in the study areas [7].

Thus, it is important to know the prevalence, and risk factors associated with access to and practice towards self-medication among the various segments of the community to devise appropriate educational, regulatory and administrative measures in alleviating the public health risks arising from improper practices of self-medication. No data is available on the current status of access to and practice towards self-medication among health sciences students of Asella Campus of Arsi University which the current study aimed to generate. The study also provide baseline data to assist different governmental \& non-governmental institutions in establishing appropriate evidence to promote rational use of prescription and non-prescription medicines and to promote visiting to health facilities for any self-unlimited and serious conditions.

\section{Methods}

\subsection{Study Design}

A cross sectional quantitative study with three months illness recall was conducted in Arsi University College of 
Health Science regular students from January to February 2015 G.C.

\subsection{Study Setting}

Arsi University is one of the youngest higher education institutions in Ethiopia and established in 2014 by Council of Ministers. Before it became an independent university it was a branch campus of Adama Science \& Technology University with two schools previously known as school of Health Sciences and school of Agriculture located at Asella city. Currently Arsi University has five colleges, one school, one institute and one academy. The Health Science College had begun its academic service by enrolling 100 Medicine students. Currently, there are total of 627 Medicine, 106 Public Health Officer, 102 Clinical Nursing, 143 Midwifery and 13 Anesthesia students at different level of year of study.

\subsection{Sampling Procedures}

Stratified sampling technique was employed based on field of studies and their academic year. All department of Arsi University College of Health Science were listed. The departments were again stratified in to different years of study and sections. Population Proportion to Size was allocated the study subject for each stratum. Based on the sampling frame (roster of each department), systematic random sampling techniques was employed to identify each study subject using a sampling interval $(\mathrm{k})$ of 2 .

\subsection{Sample Size}

Assumption one: The sample size determination for the first objective (determining prevalence of self-medication) was based similar study taken from Jimma University, the estimate of the prevalence self-medication among the general population (P) of 45.9\% [4]. Hence; considering this prevalence sample size was calculated as follow [8]:

$$
n i=\frac{Z_{a / 2}^{2} p(1-p)}{d^{2}}
$$

where, $n i=(1.96) 2 \times 0.459(1-0.459) /(0.05)^{2}=382$.

With population correction formula: $\mathrm{n}=[\mathrm{ni}(1+(\mathrm{ni} / \mathrm{N})]$, where $\mathrm{N}=991$ (total number of regular students in Arsi University College of Health Science) this gives us n to 276 and $15 \%$ for non-response (refusal to be enrolled and drop outs) makes the sample size 317.

Assumption two: The sample size for the second objective (investigating factors for self-medication) was calculated based two proportions formula [9]. Among the different predictors of self-medication, gender has the maximum yield to estimate the required sample size. A power of $80 \%$, a $5 \%$ of level of significance and ratio 1:1 (exposed and unexposed) were assumed. Moreover, the assumption on magnitudes includes a $43.4 \%$ of males and $56.3 \%$ of females university students in South Western Nigeria was reported practices of self-medication [10]. Hence; using EPI Info version 3.5.2 statistical program (CDC, Atlanta, Georgia, USA), the final sample size of the study was 575 ( $500+15 \%$ non-response rate) which produce the largest sample size of the two objectives.

\subsection{Data Collection Tools}

The data were collected using a structured self-administered questionnaire developed from literature of previous similar studies according to the objectives of the study [3] [4] [6] [11] [12]. The data were collected with trained data collectors. The questionnaires had socio demographic information, practice, knowledge and attitude on self-medication. Moreover, to maintain the quality of data the questionnaires were pre-tested in Arsi University College of Health Science extension students.

\subsection{Data Analyses}

The data collected was checked for completeness and consistency; arrangement was made to enter data after each day field work was completed. Data entry was made using Epi-Info version 3.5.2 (CDC, Atlanta, Georgia, USA) \& data analysis was done using Statistical Package for Social Science Research (SPSS IBM Version 20) 
[13]. The descriptive finding was presented with tables and graphs. Uni-Variable statistical tests were computed to identify all possible predictor variables.

In this study the dependent variable was access to self-medication. For regression analysis accessed self-medication coded as " 1 " and otherwise " 0 ". The age of students were categorized into two i.e. $<=21$ and $>=22$ years. The younger age group was taken as a reference population in the logistics regression analysis. Gender was a nominee variable and males were taken as a reference group. With regards to years of study of students those who are in their sixth years of study scored " 0 " while the rest lowest achievements get "1". Similarly, field of studies were considered as independent factor and those students studying medicine got a code " 0 " while students of Midwifery, Nursing, Public Health Officer and Anesthesia category coded "1". Students who had a positive attitude towards self-medication for low income segment of the population coded " 1 " and otherwise " 0 ". And those students who had a positive attitude towards self-mediation and prospective health care professionals coded " 1 " and otherwise "0".

\subsection{Ethical Consideration}

The research proposal was submitted to Research Review Board and ethical clearance was obtained from Addis Continental Institute of Public Health (ACIPH) and Adama Science and Technology University (ASTU). Informed consent was obtained from each study participants after explaining the purpose, objective and benefit of the study for each participant before giving them the questionnaire. Participants were free to withdraw themselves from participation at any time and participant was given the questionnaire privately as much as possible. Participant's anonymity or confidentiality was maintained.

\section{Result}

Of the total of 575 questionnaires distributed to be filled by respondents, 548 were filled collected back and assessed as complete, which gives the response rate of 95.3\%. While, 27 (4.7\%) constitutes incomplete, refusal \& reluctant responses.

\subsection{Socio-Demographic Data}

Sex, age, department and study year distribution of those who had episodes of illnesses in the specified period was shown in Table 1. Five hundred forty eight students were covered during the study period and 388 (70.8\%) of them had faced health-related problems within the last three months prior to the study. Sex distribution of those who had illness during study period showed that two hundred seventy five (70.90\%) were males and 113 (29.10\%) were females. They were predominantly young with a mean age of 21.57 (SD 2.012) years (range 18 27 years) and median age was 21 years. 250 (64.4\%), 48 (12.40\%), 40 (10.30\%), 47 (12.1\%) and 3 (0.80\%) were from the Departments of Medicine, Midwife, Nursing, Public Health and Anesthesia, respectively. In terms of their study year distribution 95 (24.50\%), 138 (35.60\%), 51 (13.10\%), 33 (8.5\%), 34 (8.8\%) and 37 (9.50\%) were from first, second, third, fourth, fifth and sixth year students respectively (Table 1).

\subsection{Prevalence of Self-Medication}

The prevalence of self-medication for this study is $P=77.1 \%, 95 \%$ CI $=73$ - 81 that is, of 388 students reported illness, 299/388 were self-medicated.

\subsection{Illness and Medications for Self-Medication}

The most common types of ailments for which the respondents reported to have accessed drugs for self-medication were headache, followed by gastrointestinal, respiratory, menstrual, eye, skin and sexually transmitted diseases with the respective episode prevalence of 169 (56.50\%), 102 (34.10\%), 95 (31.80\%), 28 (29.20\%), 67 (22.40\%), 52 (17.40\%) and 31 (10.40\%) (Table 2).

Drugs or drug groups commonly used for self-medication among 299 students was shown in Table 2. The most common drugs used in self-medication was antibiotics 179 (59.90\%) which were used for self-medication in the preceding three months. Others were analgesics constituting 143 (47.80\%), followed by gastrointestinal drugs 86 (28.80\%), respiratory drugs 74 (24.70\%), vitamins 66 (22.10\%), and ORS 50 (16.70\%). 
Table 1. Socio-demographic characteristics students of College of Health Science Arsi University, Asella, Ethiopia, February $2015(\mathrm{n}=548)$.

\begin{tabular}{|c|c|c|}
\hline Variables & Frequency & Percent \\
\hline \multicolumn{3}{|l|}{ Sex } \\
\hline Male & 397 & 72.4 \\
\hline Female & 151 & 27.6 \\
\hline \multicolumn{3}{|c|}{ Age category in years } \\
\hline $18-21$ & 295 & 53.8 \\
\hline $22-30$ & 253 & 46.2 \\
\hline \multicolumn{3}{|l|}{ Department } \\
\hline Medicine & 348 & 64.4 \\
\hline Midwifery & 77 & 14.1 \\
\hline Public Health & 59 & 11.3 \\
\hline Nursing & 58 & 10.6 \\
\hline Anesthesia & 6 & 1.1 \\
\hline \multicolumn{3}{|l|}{ Year of study } \\
\hline First year & 130 & 23.7 \\
\hline Second Year & 185 & 33.8 \\
\hline Third year & 72 & 13.1 \\
\hline Fourth year & 40 & 7.3 \\
\hline Fifth year & 62 & 11.3 \\
\hline Sixth year & 59 & 10.8 \\
\hline \multicolumn{3}{|c|}{ Illness during the previous three months } \\
\hline Yes & 388 & 70.8 \\
\hline No & 160 & 29.2 \\
\hline \multicolumn{3}{|c|}{ Have you accessed self-medication ${ }^{*}$} \\
\hline Yes & 299 & 77.0 \\
\hline No & 89 & 23.0 \\
\hline
\end{tabular}

NB: ${ }^{*}$ where $\mathrm{n}=388$.

Table 2. Illness/indications and medications for self-medication, Arsi University/College of Health Science, Asella, Ethiopia, February 2015 G.C $(n=299)$.

\begin{tabular}{|c|c|c|}
\hline Variables & Frequency & Percent \\
\hline \multicolumn{3}{|c|}{ Illness (indications) for self-medication } \\
\hline Headache/fever & 169 & 56.5 \\
\hline Gastrointestinal disease & 102 & 34.1 \\
\hline Respiratory tract infection & 95 & 31.8 \\
\hline Eye disease & 67 & 22.4 \\
\hline Skin diseases or injury & 52 & 17.4 \\
\hline Sexually transmitted disease & 31 & 10.4 \\
\hline Maternal/menstrual & 28 & 29.2 \\
\hline \multicolumn{3}{|c|}{ Drugs accessed for self-medication } \\
\hline Antibiotics & 179 & 59.9 \\
\hline Analgesics or antipyretics & 143 & 47.8 \\
\hline Gastrointestinal drugs & 86 & 28.8 \\
\hline Respiratory tract infection drugs & 74 & 24.7 \\
\hline Vitamins & 66 & 22.1 \\
\hline ORS & 50 & 16.7 \\
\hline
\end{tabular}

NB: Numbers do not add to $100 \%$ as patients might have more than 1 choice. 


\subsection{Sources of Medications and Information on Self-Medication and Reasons for Using Self-Medication}

Most of the drugs for self-medication were obtained from drug outlets 184 (61.50\%), shop/supermarkets 89 (29.80\%), relatives/friends $72(24.10 \%)$ and left over from previous drugs 57 (19.1\%). The study participants were asked about their source of information on self-medication and almost half 154 (51.5\%) students learned self-medication from own experience, followed by 98 (32.8\%) advise form pharmacy professions (Figure 1). The major reasons indicated for self-medication by respondents were: they perceived their illness as mildor disease not serious 132 (44.1\%), followed by poor quality of routine health care services at university clinic 81 (27.1\%) and it saves their time 60 (20.3\%) (Figure 2).

\subsection{Result of Uni-Variable and Multi Variable Logistic Regression Analyses}

Table 3 showed the descriptive association between socio-demographic characteristics and self-medication behavior in the past three months. Out of 388 respondents reported illness during the study period, $299(P=77.1 \%$, $95 \%$ CI $=73-81)$ respondents reported self-medicated. Self-medication was practiced by of 185 (74\%) of medicine, 43 (89.6\%) of midwife, 35 (87.50\%) of nursing, 34 (72.30\%) of public health and 2 (66.7\%) of anesthesia students. By the year of study, $24.50 \%$ of first year; $35.60 \%$ of second year; $13.10 \%$ of third year; $7.70 \%$ of fourth year, $9.5 \%$ of fifth year and $9.50 \%$ of sixth year students practiced self-medication from October to December, 2014 G.C in Arsi University, College of Health Science. This study assessed factors associated with uptake Self-medication. A logistic regression model was used to examine factors associated with self-medication as dependent variable. In the uni-variable logistic regression analysis, self-medication was found statistically significant associated with sex $(\mathrm{COR}=2.00 ; 95 \% \mathrm{CI}=1.12-3.58, P=0.019)$, midwife students was found
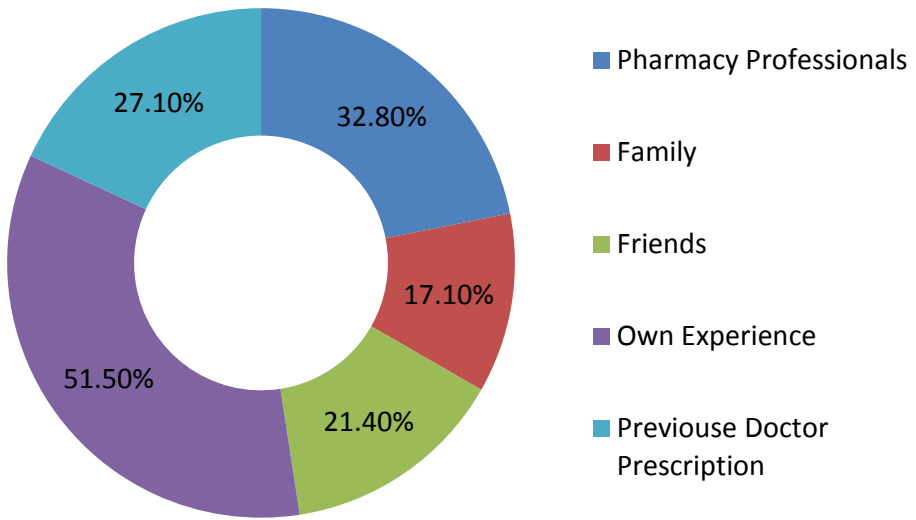

Figure 1. Sources of information for self-medication Arsi University/College of Health Sciences, Asella, Ethiopia, February 2015 ( $n=299)$ NB: Proportion don’t add up to $100.0 \%$, due to multiple answer.

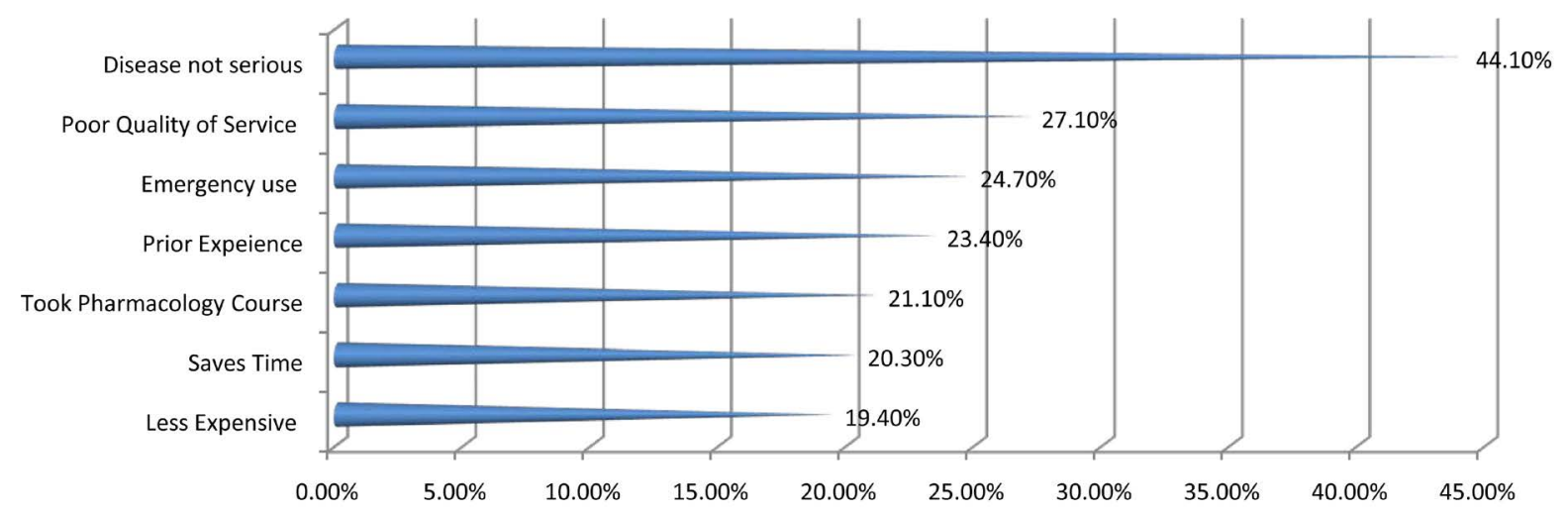

Figure 2. Reasons for self-medication Arsi University/College of Health Sciences Students, Asella, Ethiopia, February 2015 ( $n=299)$ NB: Proportion doesn’t add up to $100.0 \%$, due to multiple answers. 
Table 3. Characteristics associated with use of self-medication Arsi University/College of Health Science Asella, Ethiopia, February $2015(\mathrm{n}=388)$.

\begin{tabular}{|c|c|c|c|c|c|c|}
\hline \multirow{2}{*}{ Characteristics } & \multirow{2}{*}{ Category } & \multicolumn{2}{|c|}{ Self-Medication } & \multirow{2}{*}{ - Crude OR } & \multirow{2}{*}{$95 \% \mathrm{CI}$} & \multirow{2}{*}{ P-Value } \\
\hline & & Yes (\%) & No (\%) & & & \\
\hline \multicolumn{7}{|l|}{ Sex } \\
\hline & Female & $96(85.0 \%)$ & $17(15.0 \%)$ & 2.00 & $(1.12,3.58)$ & 0.019 \\
\hline & Male & 203(73.8\%) & $72(26.2 \%)$ & 1 & & \\
\hline \multicolumn{7}{|l|}{ Age } \\
\hline & $>=22$ & $126(73.7 \%)$ & $45(26.3 \%)$ & 0.712 & $(0.44,1.15)$ & 0.161 \\
\hline & $<=21$ & 173(79.9\%) & $44(20.3 \%)$ & 1 & & \\
\hline \multicolumn{7}{|l|}{ Field of study } \\
\hline & Midwifery & 43(89.6\%) & $5(10.4 \%)$ & 3.02 & $(1.15,7.96)$ & 0.025 \\
\hline & Nursing & $35(87.5 \%)$ & $5(12.5 \%)$ & 2.46 & $(0.92,6.55)$ & 0.072 \\
\hline & Public health & $34(72.3 \%)$ & $13(27.7 \%)$ & 0.92 & $(0.46,1.85)$ & 0.813 \\
\hline & Anesthesia & $2(66.7 \%)$ & $1(33.3 \%$ & 0.70 & $(0.06,7.88)$ & 0.775 \\
\hline & Medicine & $185(74 \%)$ & $65(26 \%)$ & 1 & & \\
\hline \multicolumn{7}{|l|}{ Year of study } \\
\hline & First & 78(82.1\%) & $17(17.9 \%)$ & 1 & & \\
\hline & Second & $103(74.6 \%)$ & $35(25.4 \%)$ & 0.64 & $(0.34,1.23)$ & 0.18 \\
\hline & Third & $39(76.5 \%)$ & 12(23.5\%) & 0.71 & $(0.31,1.63)$ & 0.417 \\
\hline & Fourth & $22(66.7 \%)$ & 11(33.3\%) & 0.44 & $(0.18,1.07)$ & 0.069 \\
\hline & Fifth & $26(76.5 \%)$ & $8(23.5 \%)$ & 0.71 & $(0.27,1.83)$ & 0.477 \\
\hline & Six & 31(83.8\%) & $6(16.2 \%)$ & 1.13 & $(0.41,3.12)$ & 0.819 \\
\hline \multicolumn{7}{|c|}{ Self-medication is accepted for low income segment of population } \\
\hline & Agree & $106(82.8 \%)$ & $22(17.2 \%)$ & 1.67 & $(0.98,2.86)$ & 0.06 \\
\hline & Disagree & 193(74.2\%) & $67(25.8 \%)$ & 1 & & \\
\hline \multicolumn{7}{|c|}{ Health science students have the right to self-medicate } \\
\hline & Agree & 191(77.3\%) & $56(22.7 \%)$ & 1.04 & $(0.64,1.70)$ & 0.869 \\
\hline & Disagree & $108(76.6 \%)$ & $33(23.4 \%)$ & 1 & & \\
\hline
\end{tabular}

to be self-medicated three times greater than other departments $(\mathrm{COR}=3.20 ; 95 \% \mathrm{CI}=1.15-7.96, P=0.025)$. Whereas self-medication was not statistically significantly associated with year of study $(P>0.05)($ Table 3$)$.

Since factors like sex, age, field of study and attitude toward self-medication (Self-medication is accepted for low income) has $P$-value less than or equal to 0.2 , a multivariate analysis was then carried out to evaluate the effect of adjusted variables on each other against the dependent variable. The odds of being female university student was 2 fold accessed self-medication than their counter part males with Adjusted Odds Ratio (AOR) 1.84 with 95\% Confidence Interval (CI) : $1.01-3.34, P=0.046$. With regards to field of studies, students of midwifery were 3 folds accessed self-medication than their counter part students of medicine (AOR 2.78; 95\%CI = 1.03, 7.39, $P=0.043$ ). Those students who accepted self-medication for low income segment of the population 2 folds accessed self-medication than their counter part who disagree (AOR 1.76; 95\%CI $=1.02,3.06, P=0.04$ ) (Table 4). 
Table 4. Multivariate Analyses of factors affecting self-medication Arsi University/College of Health Science Asella Ethiopia, February $2015(n=388)$.

\begin{tabular}{|c|c|c|c|c|c|c|c|}
\hline \multirow{2}{*}{ Characteristics } & \multirow{2}{*}{ Category } & Self-Medication & \multirow{2}{*}{ COR } & \multirow{2}{*}{$95 \% \mathrm{CI}$} & \multirow{2}{*}{ AOR } & \multirow{2}{*}{$95 \%$ CI } & \multirow{2}{*}{ P-Value } \\
\hline & & Yes (\%) & & & & & \\
\hline \multicolumn{8}{|l|}{ Sex } \\
\hline & Female & 96 (85\%) & 2.00 & $(1.12,3.58)$ & 1.84 & $(1.01,3.34)$ & 0.046 \\
\hline & Male & 203 (73.8\%) & 1 & & 1 & & \\
\hline \multicolumn{8}{|c|}{ Age group (in years) } \\
\hline & $>=22$ & $126(73.7 \%)$ & 0.712 & $(0.44,1.15)$ & 0.80 & $(0.47,1.34)$ & 0.41 \\
\hline & $<=21$ & $173(79.9 \%)$ & 1 & & 1 & & \\
\hline \multicolumn{8}{|l|}{ Field of study } \\
\hline & Midwifery & 43 (89.6\%) & 3.02 & $(1.15,7.96)$ & 2.76 & $(1.03,7.39)$ & 0.043 \\
\hline & Nursing & 35 (87.5\%) & 2.46 & $(0.92,6.55)$ & 1.98 & $(0.72,5.45)$ & 0.188 \\
\hline & Public Health & 34 (72.3\%) & 0.92 & $(0.46,1.85)$ & 0.82 & $(0.39,1.76)$ & 0.937 \\
\hline & Anesthesia & $2(66.7 \%)$ & 0.70 & $(0.06,7.88)$ & 0.91 & $(0.08,10.33)$ & 0.937 \\
\hline & Medicine & $185(74 \%)$ & 1 & & 1 & & \\
\hline \multicolumn{8}{|c|}{ Self-medication is accepted for low income segment of the population } \\
\hline & Agree & $106(82.8 \%)$ & 1.67 & $(0.98,2.86)$ & 1.76 & $(1.02,3.06)$ & 0.044 \\
\hline & Disagree & $193(74.2 \%)$ & 1 & & 1 & & \\
\hline
\end{tabular}

NB: COR: Crude Odds Ratio; AOR: Adjusted Odds Ratio; CI Confidence Interval.

\section{Discussion}

Although responsible self-medication is the practice whereby individuals treat their ailments and conditions with medicines which are approved and available without prescription, and which are safe and effective when used as directed, it will lead to unintended effect if inappropriately used. The result from this study revealed that the prevalence of self-mediation among students reported illness was 299 (77.10\%) which was similar to the study conducted in India with prevalence of 78.62\% [10]. Recent similar studies conducted in different areas such as the Gondar [7], Mekele [3], Jimma [4], Nigeria [14] and Pakistan [5] vary in their estimation of the percentage of patients who practice self-medication, with prevalence rates that range from about $38.5 \%$ to $95.5 \%$. Comparing the results of the present study with those in the literature is difficult since studies differ in their definitions of self-medication and in the methodologies employed and countries also differ in their cultures, health care systems and the perceived role of pharmacists. However, there is a general agreement among these studies that self-medication has potential risks and that despite efforts exercised by health care professionals and decision makers to limit this problem, rates of self-medication are on the rise.

The data from the present study indicated that sex had a significant independent association with the practice of self-medication that is females were more inclined to self-medication than men $(P<0.05)$ which was similar to studies conducted Mekele [3] but contradicts results reported by other study in Gondar [7].

Despite the fact that the respondents' level of education and field of study were not significant factors in the bivariate analysis (but the result revealed self-medication was significant for midwife students $P<0.05$ and the percentage of self-medication was lower as year of study increased i.e. gaining more clinical and drug knowledge may contributed for this result). The study conducted in Mekele \& Gondar [3] [7] contradicts our findings, which reported that the level of education and field of study has an impact on the practice of self-medication.

Headache, a predisposing factor, was the primary symptoms for practicing self-medication 169 (56.50\%) which were supported by the study elsewhere reported 60\% in Addis Ababa town [9], 62.30\% in Karachi University [15] 60\% in India [16]. 
Non-seriousness of the illness \& saving time was the two major reasons of self-medication in this study. This result was expected as university students are busy of learning activities. So the university clinic needs to find ways by which it will decrease waiting time to see physicians. Factors like emergency use, cost, prior experiences, and knowledge of pharmacology \& service quality are frequently reported in literature and different surveys [17]. Study conducted in India showed that conventional idea and time saving were two most common reasons for self-medication among all students [18]. Another studies conducted in India reported that lack of time, quick relief from illness, ease \& convenience was some of the reason for self-medication [19].

Drug consumers were asked as to their source of advice/information for self-medication. The results revealed that the major source for self-medication were their own experience \& advice of the pharmacy professionals but without formal prescription. Other studies carried out in India reported that the three most important sources of drug information among all students were books, family members and seniors \&friends [18].

In this study most of drugs were accessed from drug outlets (61.5\%). Drugs retail outlets (40.40\%); relative/ friends (15.63\%) and open market (14.10\%) were reported in a similar study done in Mekele University [3]. In this study it was found that $64.7 \%$ of the students visiting drug outlets twice or more. So there should be strong a system to restrict drug outlets from dispensing of prescription only medicine without prescription. The availability of drugs in informal sectors such as open markets and kiosks (shops) encourage the rampant practice of self-medication. In order to decrease unnecessary health risk and bacterial resistance due to improperly obtained and used drugs, it is important to consider the manners of drug availability to consumers.

The study revealed that 238 (79.60\%) of self-medicated students were able to recall the name of drug(s) they used which was higher than the study done in Jimma town 73.8\% [11]. This might be the students have better knowledge to remember the name of drug(s) than the community peoples in Jimma town.

Our study revealed thatantibiotics (59.90\%), analgesics (47.80\%), gastrointestinal drugs (28.80\%) and respiratory drugs (24.70\%) were the mostcommon self-medicated group of drugs. Other similar studies carried out in India reported that $91 \%$ analgesics while $53.5 \%$ antibiotics [20]. There may be two major problems regarding self-medication with analgesics. The first is the possible risk of nephropathy and possible drug-induced gastric ulceration. In this study ADR was reported by 33(11\%) of the respondents of which more than $90 \%$ mentioned that it was gastric irritation. The second is overuse of analgesics like paracetamol, aspirin or other NSAIDs especially when given in combination since they increase the risk of chronic toxicity among patients. In this study $67.2 \%$ of students self-medicated twice or more. Similar adverse results of self-medication with antibiotics have been reported in other countries [12]. This might be due to the access of prescription and nonprescription drugs from drug outlets and negligence of pharmacy professionals about regulatory policy of prescription and OTC drugs and poor usage of antimicrobials. The study result revealed that from self-medicated students, 163 (54.50\%) didn't finish the drug(s) already started which was almost similar with study done in Jimma University (47.37\%) [4]. Even though the major reason given from the respondents were immediate relief 109 (66.90\%) from their illness, this might cause risk of pathogenic resistance especially with antimicrobials, and further complicates the illness.

Finally, the study result revealed that from all respondents participated in the study, 347 (63.30\%) of students believe that "Students of health science have the right to prescribe medicine for their own consumption" and 358 (65.30\%) students believed that self-medication is the accepted way of addressing health problems for low income segment of the population $(P<0.05)$, this might be a means for drug interaction with regular medicine, drug resistance for antimicrobials, masking and complication of illnesses and increase irrational use of medicines.

\section{Conclusion}

In conclusion, a significant number of students, $77.1 \%$, accessed to and practiced self-medication among those reported illness during the study period. Female university students had more practice of self-medication than their counter part males. Headache and gastrointestinal disease were the most commonly reported conditions for self-medication practices in the current study. Antibiotics and analgesics were the most commonly reported types of medications consumed in self-medications, drug retail outlets were the major sources of drugs and contributed to increasing practice for self-medication. The major reasons indicated for self-medication by respondents were their perceived towards their illness as it is mild, the quality of health care at university clinics is poor and self-medication saves their time. Most respondents believed to practice self-medication as they are 
health professionals \& also they considered it as right to practice for low income segments of the populations. Finally, to address this high prevalence of self-medication and promote rational drug use among university health science students, conducting tailored behavioral change communication strategies by the health authorities, universities and other stakeholders is recommended. In addition, the gender difference observed in this study, investigators recommended an exploratory qualitative research.

\section{Limitation}

This study is limited to self-medication practice to group/class of drugs. It didn't include each drugs used for self-medication. The questionnaire is self-reported one which may lead to under or over reporting.

\section{Acknowledgements}

The authors would like to thank respondents of the survey who voluntarily took part in this study. The authors also extend their gratitude for Wondossen Gadisa for his effort in coordinating the data collection.

\section{Competing Interest}

The author(s) declare that they have no competing interests.

\section{Author's Contribution}

The authors responsible were SAB, MDA \& AWY. SAB have made substantial contributions to conception and design, or acquisition of data, or analysis and interpretation of data. MDA have been involved through the whole process of this research activity. AWY have been involved in revising it critically for important intellectual content. MDA the corresponding author submitted the paper for publication.

\section{References}

[1] Ali, A.N., Kion, J.T., Keat, C.C. and Dhanaraj, S.A. (2012) Self-Medication Practices among Health Care Professionals in a Private University, Malaysia. International Current Pharmaceutical Journal, 1, 302-310. http://dx.doi.org/10.3329/icpj.v1i10.11846

[2] Alghanim, S.A. (2011) Self-Medication Practice among Patients in a Public Health Care System. EMHJ, 17, 409-416.

[3] Gutema, G.B., Gadisa, D.A., Kidanemariam, Z.A., Berhe, D.F., Hadera, M.G., Hailu, G.S., et al. (2011) Self-Medication Practices among Health Sciences Students: The Case of Mekelle University. Journal of Applied Pharmaceutical Science, 1, 183-189.

[4] Angamo, M.T. and Wabe, N.T. (2012) Knowledge, Attitude and Practice of Self Medication in Southwest Ethiopia. IJPSR, 3, 1005-1010.

[5] Ullah, H., Khan, S.A., Ali, S., Karim, S., Baseer, A., Chohan, O., et al. (2013) Evaluation of Self-Medication amongst University Students in Abbottabad, Pakistan; Prevalence, Attitude and Causes. Acta Poloniae Pharmaceutica Drug Research, 70, 919-922.

[6] Andualem, T. and Gebre-Mariam, T. (2004) Self-Medication practice in Addis Ababa; Ethiopia. Journal of Health Sciences, 14, 1-11.

[7] Abay, S.M. and Amelo, W. (2010) Assessment of Self-Medication Practices among Medical, Pharmacy, and Health Science Students in Gondar University, Ethiopia. Journal of Young Pharmacists, 2, 306-310. http://dx.doi.org/10.4103/0975-1483.66798

[8] Bartlett, J.E., Kotrlik, J.W. and Higgins, C.C. (2001) Organizational Research: Determining Appropriate Sample Size in Survey Research. Information Technology, Learning, and Performance Journal, 19, 43-50.

[9] Pagano, M., Gauvreau, K. and Pagano, M. (2000) Principles of Biostatistics (Vol. 2). Duxbury, Pacific Grove.

[10] Lokanath, N., Romnanth, S., Balavardhan, S.N., Kiran, K.R. and Mohamed, S.T. (2012) Evaluation of Self-Medication among Professional Students of Rajampet. International Journal of Research in Pharmaceutical Sciences, 3, 1-5.

[11] Worku, S. and G/Mariam A. (2003) Practice of Self-medication in Jimma Town. Ethiopian Journal of Health Development, 17, 111-116.

[12] Sawalha, A.F. (2007) Assessment of Self-Medication Practice among University Students in Palestine: Therapeutic and Toxicity Implications. The Islamic University Journal, 15, 67-82.

[13] SPSS, I. (2011) IBM SPSS Statistics Base 20. SPSS Inc., Chicago. 
[14] Osemene, K.P. and Lamikanra, A. (2012) A Study of the Prevalence of Self-Medication Practice among University Students in Southwestern Nigeria. Tropical Journal of Pharmaceutical Research, 11, 683-689. http://dx.doi.org/10.4314/tjpr.v11i4.21

[15] Mumtaz, Y., Jahangeer, S.M., Mujtaba, T., Zafar, S. and Adnan, S. (2011) Self-Medication among University Students of Karach. JLUMHS, 10, 103-105.

[16] Badiger, S., Kapur, R., Jain, A., Kumar, A., Pattanshetty, S., Thakolkaran, N., et al. (2012) Self-Medication Patterns among Medical Students in South India. AMJ, 5, 217-220. http://dx.doi.org/10.4066/AMJ.2012.1007

[17] Jain, P., Sachan, A., Singla, R.K. and Agrawal, P. (2012) Statistical Study on Self Medication Pattern in Haryana, India. Indo Global Journal of Pharmaceutical Sciences, 2, 21-35.

[18] Harlalka, S., Mazumdar, G. and Roy, U.K. (2014) A Study on Evaluation of Self Medication among Undergraduate Students of Health Care Management in Eastern India. World Journal of Pharmaceutical Research, 3, 1558-1566.

[19] Balamurugan, E. and Ganesh, K. (2011) Prevalence and Pattern of Self-Medication Use in Coastal Regions of South India. BJMP, 4, a428.

[20] Gholap, M.C. and Mohite, V.R. (2013) Assess The Self Medication Practices Among Staff Nurses. Indian Journal of Scientific Research, 4, 81-84. 


\section{Annexure}

\section{Self-Administered Questionnaire Instructions:}

This is the questionnaire of the self-medication practice study you've been kind enough to participate in. We ask you to please fill out this questionnaire made of two sections. The first parts are general information about your profile. Then, there is an entire section about your self-medication practice in the last three months. The results of the study would be used to identify the gaps with regard to self-medication practice so please fill the questioner appropriately.

Your answers are absolutely confidential. They will be seen only by people held to professional secrecy, and the information will be treated anonymously. Please answer the questions in the order they're given; at the bottom of each page check if you've answered them all before you turn the page.

If you feel tired, take a short break. If something is not clear, don't hesitate to ask for an explanation from the person who gave you the questionnaire.

Section I. Demographic characteristics of the respondents.

\begin{tabular}{ccc}
\hline S. No & Question & Responses \\
\hline 101 & Sex & Male \\
102 & Age & Female \\
& & years \\
103 & Field of study & 1. Medicine 2. Midwife \\
104 & Year of study & 3. Nursing 4. Pharmacy \\
105 & Average monthly income & birr \\
106 & Monthly Drug expenditure & birr \\
\hline
\end{tabular}

Section II. Prospective of Self-Medication.

\begin{tabular}{|c|c|c|c|c|c|}
\hline \multicolumn{6}{|c|}{ Self-medication pattern } \\
\hline S. No & Question & \multicolumn{3}{|l|}{ Responses } & Skip to... \\
\hline 200 & $\begin{array}{l}\text { Have you experienced } \\
\text { any illness during the } \\
\text { previous three months }\end{array}$ & \multicolumn{3}{|l|}{$\begin{array}{l}\text { Yes } \\
\text { No }\end{array}$} & 401 \\
\hline 201 & $\begin{array}{l}\text { Have you ever treated yourself } \\
\text { (self-medicated) with drugs } \\
\text { in the last three months? }\end{array}$ & \multicolumn{3}{|l|}{$\begin{array}{l}\text { Yes } \\
\text { No }\end{array}$} & $\begin{array}{l}\text { If no skip } \\
\text { to Q301 } \\
\text { of part B }\end{array}$ \\
\hline \multirow[t]{4}{*}{202} & $\begin{array}{l}\text { How many times did you } \\
\text { treat yourself with drugs in } \\
\text { ]]the past three months? }\end{array}$ & & & & \\
\hline & & Response & Yes & No & \\
\hline & & $\begin{array}{l}\text { 1. Respiratory Tract Infection } \\
\text { (E.g. cough, cold, etc.) }\end{array}$ & 1 & 2 & \\
\hline & & 2. Eye disease & 1 & 2 & \\
\hline \multirow{6}{*}{203} & For which of the & 3. Gastrointestinal disease & 1 & 2 & \\
\hline & $\begin{array}{l}\text { following complaint(s) } \\
\text { did vou use drugs? }\end{array}$ & 4. Sexually transmitted disease & 1 & 2 & \\
\hline & & 5. Headache/Fever & 1 & 2 & \\
\hline & & 6. Skin disease/Injury & 1 & 2 & \\
\hline & & 7. Maternal/Menstrual & 1 & 2 & \\
\hline & & 8. Others & 1 & & \\
\hline
\end{tabular}




\section{Continued}

204

205

206

207

208

209
What was (were) your reason(s) of self-medication with drugs?

Your selection of drugs was based on recommendation from

Where did you usually obtain drugs for self-medication?

List drugs most recently used for self-medication

If your source of drugs is drug outlets, How frequent did you visit drug outlets to purchase drugs without prescription for yourself over the last 3 months?

Have you ever had any adverse reaction when you took drugs for self-medication?

What was the outcome the treatment with self-medication?

\begin{tabular}{|c|c|c|c|}
\hline \multicolumn{2}{|l|}{ Response } & Yes & No \\
\hline \multicolumn{2}{|l|}{ 1. Emergency use } & 1 & 2 \\
\hline \multicolumn{2}{|l|}{ 2. Disease not serious } & 1 & 2 \\
\hline \multicolumn{2}{|l|}{ 3. Less expensive } & 1 & 2 \\
\hline \multicolumn{2}{|l|}{ 4. Saves time } & 1 & 2 \\
\hline \multicolumn{2}{|l|}{ 5. Prior experience } & 1 & 2 \\
\hline \multicolumn{2}{|l|}{ 6. Took pharmacology course } & 1 & 2 \\
\hline \multicolumn{2}{|c|}{ 7. Poor quality services at University clinic } & 1 & 2 \\
\hline \multicolumn{2}{|l|}{ 8. Others } & \multicolumn{2}{|l|}{1} \\
\hline Response & Yes & & No \\
\hline 1. Pharmacy professionals & 1 & & 2 \\
\hline 2. Family & 1 & & 2 \\
\hline 3. Friends & 1 & & 2 \\
\hline 4. Own experiences & 1 & & 2 \\
\hline 5. Previous doctor's prescription & 1 & & 2 \\
\hline 6. Others & 1 & & \\
\hline Response & Yes & & No \\
\hline 1. Drug out lets & 1 & & 2 \\
\hline 2. Shops/Supermarkets & 1 & & 2 \\
\hline 3. Relatives/Friends & 1 & & 2 \\
\hline 4. Left over from previous medicine & 1 & & 2 \\
\hline 5. Others & 1 & & \\
\hline
\end{tabular}

1. Specify

1. Yes, Please Specify

2. No

\begin{tabular}{|c|c|c|}
\hline Response & Yes & No \\
\hline 1. Cured the illness & 1 & 2 \\
\hline 2. Prevented the illness & 1 & 2 \\
\hline 3. Improved the illness & 1 & 2 \\
\hline $\begin{array}{l}\text { 4. Neither cured, prevented } \\
\text { or improved the illness }\end{array}$ & 1 & 2 \\
\hline 5. Others & 1 & \\
\hline
\end{tabular}




\section{Continued}

$211 \quad \begin{aligned} & \text { What is your solution } \\ & \text { if self-medication didn't } \\ & \text { brought relief of illness? }\end{aligned}$

S. No

Question

B. Knowledge

\begin{tabular}{|c|c|c|}
\hline \multicolumn{3}{|l|}{ Responses } \\
\hline Response & Yes & No \\
\hline 1.By mentioning the name of the drug & 1 & 2 \\
\hline 2. By mentioning the class of the drug & 1 & 2 \\
\hline 3. By Telling symptoms of illness & 1 & 2 \\
\hline 4. By showing old package & 1 & 2 \\
\hline $\begin{array}{l}\text { 5. By describing shape or other } \\
\text { characteristics of the drug }\end{array}$ & 1 & 2 \\
\hline 6. Others & 1 & 2 \\
\hline Response & Yes & No \\
\hline 1. Antibiotics & 1 & 2 \\
\hline 2. Analgesics/Antipyretics & 1 & 2 \\
\hline 3. Respiratory drugs & 1 & 2 \\
\hline 4. Gastrointestinal drugs & 1 & 2 \\
\hline 5. Vitamins & 1 & 2 \\
\hline 6. ORS (Oral Rehydration Salt) & 1 & 2 \\
\hline 7. Others & 1 & \\
\hline Response & Yes & No \\
\hline 1. Name of the drug & 1 & 2 \\
\hline 2. Dose & 1 & 2 \\
\hline 3. Indication & 1 & 2 \\
\hline 4. Frequency & 1 & 2 \\
\hline 5. Duration & 1 & 2 \\
\hline 6. How to use (e.g. shaking) & 1 & 2 \\
\hline 7. Storage at home & 1 & 2 \\
\hline 8. Others & & \\
\hline
\end{tabular}

Skip to...

301

302

303

304

305
How did you request the drug(s) you want?

What type of drug(s) you requested?

What do you know about the drug you requested?

Did you finish the drugs you took for self-medication?

What was reason for not finishing?

\section{Yes}

No

If yes go to section C Q401 


\section{Continued}

\begin{tabular}{|c|c|c|c|}
\hline \multicolumn{4}{|c|}{ C. Attitude } \\
\hline S. No & Question & Responses & Skip to... \\
\hline 401 & $\begin{array}{l}\text { “Self-medication is the } \\
\text { accepted way of addressing } \\
\text { health problems for low } \\
\text { income segment of the } \\
\text { population”. What is } \\
\text { your opinion for the } \\
\text { above statement? }\end{array}$ & $\begin{array}{l}\text { 1. Strongly agree } \\
\text { 2. Agree } \\
\text { 3. No opinion } \\
\text { 4. Disagree } \\
\text { 5. Strongly disagree }\end{array}$ & \\
\hline 402 & $\begin{array}{l}\text { "Students of health studies } \\
\text { have the right to prescribe } \\
\text { medicine for their own } \\
\text { consumption". What is your } \\
\text { opinion for the above statement? }\end{array}$ & $\begin{array}{l}\text { 1. Strongly agree } \\
\text { 2. Agree } \\
\text { 3. No opinion } \\
\text { 4. Disagree } \\
\text { 5. Strongly disagree }\end{array}$ & \\
\hline
\end{tabular}

Thank you so much for your time and information.

\section{Warmly welcome your paper submission to OALib Journal!}

- Publication on a daily basis

- 9 subject areas of science, technology and medicine

- Fair and rigorous peer-review system

- Fast publication process

- Article promotion in various social networking sites (LinkedIn, Facebook, Twitter, etc.)

- Widely-targeted and multidisciplinary audience to read your research

Submit Your Paper Online: Click Here to Submit

Contact Us: service@oalib.com 